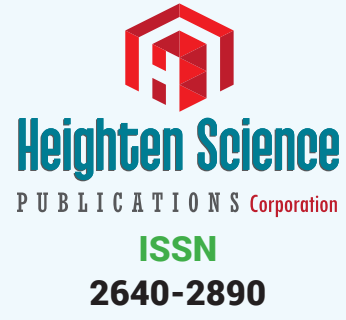

*Address for Correspondence: Josef Hyánek, Metabolická ambulance OKBHI Nemocnice $\mathrm{Na}$ Homolce, Roentgenova 2, 15030 Praha 5, Czech Republic, Tel: +420 603440 013;

Email: josef.hyanek@homolka.cz

\section{Submitted: 25 June 2019 \\ Approved: 01 July 2019 \\ Published: 02 July 2019}

Copyright: @ 2019 Hyánek J, et al. This is an open access article distributed under the Creative Commons Attribution License, which permits unrestricted use, distribution, and reproduction in any medium, provided the original work is properly cited

Keywords: Hypercholesterolemia during pregnancy; Gestational hypercholesterolemia; Familial hypercholesterolemia; Non-cholesterol sterols; Lathosterol; Desmosterol; Campesterol; Sitosterol

\section{Abbreviations: Cam: Campesterol; CS:} Caesarean Section; TC: Total Cholesterol; $\mathrm{CHD}$ : Coronary Heart Disease; Des: Desmosterol; FH: Familial Hypercholesterolemia; GH: Gestational Hypercholesterolemia; HDL: High-Density Lipoprotein; HDL-C: High-Density Lipoprotein Cholesterol; IMT: Intima Media Thickness; IUGR: Intrauterine Growth Retardation; Lat: Lathosterol; LDL: Low-Density Lipoprotein; LDL-C: Low-Density Lipoprotein Cholesterol; NCS: Non-Cholesterol Sterol; Non-HDL-C: Non-HDL Cholesterol; SHHP: Sonic Hedgehog Protein; Sit: Sitosterol; TG: Triglycerides (Triacylglycerols)

\section{Check for updates}

\title{
Gestational hypercholesterolemia helps detect familial hypercholesterolemia and prevent late pregnancy complications
}

\author{
Josef Hyánek* František Pehal', Kseniya Dryahina², Ladislava \\ Dubská', Blanka Míková', Lada Gombíková', Miroslav Průcha', \\ Stanislav Kubů ${ }^{3}$, Petra Haláčková ${ }^{3}$ and Jaroslav Feyreis ${ }^{3}$ \\ 'Department of Clinical Biochemistry, Hematology and Immunology, Na Homolce Hospital, \\ Prague, Czech Republic \\ ${ }^{2}$ Department of Chemistry of lons in Gaseous Phase, J. Heyrovský Institute of Physical \\ Chemistry, Academy of Sciences of the Czech Republic, Prague, Czech Republic \\ ${ }^{3}$ Department of Clinical Biochemistry, Central Laboratories, The Institute for the Care of Mother \\ and Child, Prague, Czech Republic
}

\section{Abstract}

Introduction: In this retrospective study, we comment on the cause and diagnostic potential of the elevated serum total cholesterol and some non-cholesterol sterols in a population of healthy pregnant women from Prague, Czech Republic.

Methods: Based on a total of 21,000 clinical biochemistry tests of healthy pregnant women with hypercholesterolemia observed during pregnancy, a testing group of 84 women with a total cholesterol (TC) above $7.0 \mathrm{mmol} / \mathrm{I}$ was established to analyze their non-cholesterol sterols (NCS) by Gas Chromatography-Mass Spectrometry. Lathosterol (Lat) and desmosterol (Des) were evaluated as markers of endogenous cholesterol synthesis, whereas campesterol (Cam) and sitosterol (Sit) were analysed as markers of intestinal absorption.

Results: In the basic population, the frequency of gestational hypercholesterolemia with the serum TC levels $>7.0 \mathrm{mmol} / \mathrm{I}$ was 1 to 136. The mean values were: TC $6.8 \mathrm{mmol} / \mathrm{I}, \mathrm{LDL}-\mathrm{C} 4.6 \mathrm{mmol} / \mathrm{I}$, and HDL-C $2.2 \mathrm{mmol} / \mathrm{I}$. In the selected testing group of 84 , the mean values were: Lat $7.8+/-1.7$ $\mu \mathrm{mol} / \mathrm{l}$, Des $4.7+/-0.9 \mu \mathrm{mol} / \mathrm{l}$, Cam $9.8+/-2.6 \mu \mathrm{mol} / \mathrm{l}$, and Sit $9.6+/-3.8 \mu \mathrm{mol} / \mathrm{l}$. Lat correlated with TC $(r=0.53)$, LDL-C $(r=0.36)$, and non-HDL-C $(r=0.35)$. No such correlations were observed for Cam or Sit.

Conclusion: Our findings prove that gestational hypercholesterolemia is caused by increased endogenous cholesterol synthesis via lathosterol. Subsequently, we demonstrate how a single cholesterol test taken in the fifth to sixth month gestation can efficiently help detect familial hypercholesterolemia, and prevent related late pregnancy circulatory complications.

\section{Introduction}

Strange and even unbelievable as it may seem, we can say in simplified terms that humans reach the highest total cholesterol (TC) levels during pregnancy as shown in figure 1 [1-3]. In pregnant women, total cholesterol (TC) normally goes up by 30 to 40 per cent, with the maximum increase occurring in the fifth to sixth gestational month. The rise in the low-density lipoprotein (LDL) cholesterol is more pronounced than in the high-density lipoprotein (HDL) fraction [4]. The occasionally detected increase in triglycerides (TG) is independent of TC levels and has different metabolic reasons.

How to cite this article: Hyánek J, Pehal F, Dryahina K, Dubská L, Míková B, et al. Gestational hypercholesterolemia helps detect familial hypercholesterolemia and prevent late pregnancy complications. Clin J Obstet Gynecol. 2019; 2: 079-089. https://doi.org/10.29328/journal.cjog.1001026 


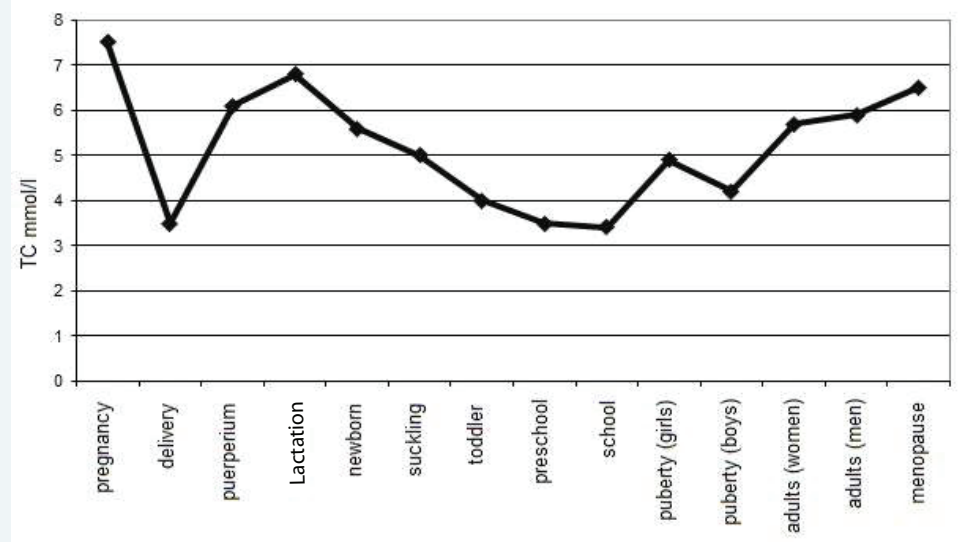

Figure 1: Total cholesterol blood values and their oscillations within human life (simplified).

Hypercholesterolemia during pregnancy, or gestational hypercholesterolemia (GH), can be found in all pregnant ethnic groups round the world, including the women of Tarahumara, a Mexican indigenous tribe with the globally lowest normal TC levels, who almost double their cholesterolemia during gestation.

In line with decades of experience, clinicians have been largely of the opinion that hypercholesterolemia during pregnancy is harmless and even beneficial for the mother and the fetus, providing for the increased cholesterol consumption in the cell membrane synthesis of the fetus, for proper organogenesis, and for due fetal as well as placental growth [5,6]. Quite recently, there have also been speculations about the higher offer and demand of the sonic hedgehog proteins (SHHP). These molecular chaperones with its C-terminal cholesterol molecule attached to the embryonal tissue induce formation of peptide bonds. In this way they metabolically initiate the increase of protein synthesis, inducing new development of certain tissues, like limbs and parts of brain. The appropriate TC concentration in blood is therefore likely to ensure the appropriate SHHP functioning in the fetal organogenesis $[7,8]$. The organogenetic significance of the palmitate molecule occupying the other SHHP terminal has not been clarified so far.

Deficit of plasma cholesterol during fetal development results in multiple organ malformations, as well as severe mental retardation and brain dysfunction. Our knowledge on disorders of this kind is still limited, and the clinical picture and metabolic description of the Smith-Opitz-Lemli, Conradi-Hunnermann, Axley-Bixlere or Greenberg skeletal dysplasia syndromes provide ample warning for anybody daring to undertake experiments in the highly complex metabolic terrain during pregnancy [9-12].

Despite the historic 1999 FELIC study defining the optimum levels of cholesterol in low-risk pregnancy to range between $3.1 \mathrm{mmol} / \mathrm{l}$ and $7.8 \mathrm{mmol} / \mathrm{l}$ [13], there has been no consensus to date on the normal reference ranges for lipid parameters across gestation. This, together with the clinicians' uncertainty as to the significance of elevated cholesterol levels for a limited time period, largely contributes to the current state of affairs, where cholesterol is not routinely measured during pregnancy, and high levels are not treated [14].

The relative increase of TC during pregnancy is the same in healthy women as in those with familial hypercholesterolemia (FH). This means in practice that in pregnant women with $\mathrm{FH}$, TC easily reaches the already pathologic levels of up to $8-9 \mathrm{mmol} / \mathrm{l}$. [15]. FH is a hereditary cholesterol metabolism disorder caused by at least 3 so far known metabolic mechanisms (i. molecularly conditioned LDL-receptor deficit / OMIM: 143890/, ii. Apo B (FBD) deficit /OMIM: 144010/, and iii. PKS9 deficit /OMIM: 
603776/). It is characterized by very high LDL cholesterol levels from birth, where a low-cholesterol diet is ineffective and those affected have a dramatically increased risk of a coronary heart disease (CHD). In its heterozygote form, untreated FH (TC 8-15 $\mathrm{mmol} / \mathrm{l}$, or $310-580 \mathrm{mg} / \mathrm{dl}$ ) usually predisposes for CHD before the age of $55 \mathrm{in}$ men and 60 in women, whereas the rare homozygous patients without treatment (TC 12$30 \mathrm{mmol} / \mathrm{l}$, or $460-1160 \mathrm{mg} / \mathrm{dl}$ ) are likely to experience CHD-induced death before the age of 20. FH is the most widespread lipid metabolism deviation in the European population, the prevalence of heterozygotes being relatively high (1 per 200-250). The homozygous form is rare, with an estimated prevalence of 1 per 160,000-300,000 (for detailed information on FH and its treatment in non-pregnants and children see Vogt [16] and Wiegman et al. [17], respectively]. Despite the metabologists' efforts, FH remains underdiagnosed and undertreated in the general population [18].

Considerably less has been written on the significance and consequences of 'gestational familial hypercholesterolemia', and our knowledge of this metabolic peculiarity remains insufficient [19-23]. The pathogenesis of GH is still poorly understood, although the placenta can use all the metabolic mechanisms of lipogenesis that have been described in non-pregnant adults [24-26]. There are chiefly case studies available of exceptional gestosis with TC levels exceeding $15 \mathrm{mmol} / \mathrm{l}$ for the rare homozygote forms of $\mathrm{FH}$, where careful monitoring and possible treatment by lipoprotein apheresis is required owing to the high risk of CHD [27-29]. Case studies of heterozygous form of FH during pregnancy are much scarcer [30]. Dilemmas in treatment of women with FH during pregnancy have been summarized by Kusters et al. [31].

We have now had over twenty five years of extensive experience with dietary and drug treatment of hypercholesterolemic children and adolescents in the outpatient lipid clinic of the Na Homolce Hospital, Prague, successfully combining standard lipid profile with non-cholesterol sterols (NCS) in the monitoring of patients. NCS are cholesterol-like metabolites revealing the long and complex endogenous synthesis of cholesterol, as well as the intricate mechanism of the sterol absorption in the intestine [32-36]. The evaluation of NCS has proven to be highly practical (a) in differentiating between FH and alimentary hypercholesterolemia, (b) in determining the size of the therapeutic statin doses, (c) in monitoring the efficacy of medication (monotherapy vs. combined therapy), and (d) for checking whether the patient is actually taking the recommended medication, as well as for verification of the actual intake of food enriched with plant sterol esters [35]. Between 1992 and 2015, 12 of our lipid clinic patients aged 19 to 45 were pregnant at least once (Table 1). Without any dietary or medical treatment, their TC levels reached $8.2+/-2.1 \mathrm{mmol} / \mathrm{l}$ during the second trimester.

When working closely a few years ago with the Central Laboratories at the Prague Institute for the Care of Mother and Child, a maternity hospital with over 5,000 deliveries per year, we were evaluating 21,000 clinical biochemistry results of healthy pregnant women. This provided us with a unique opportunity to look at GH via NCS and confirm its high prevalence among the Slavic population. Also, we wanted to prove

\begin{tabular}{|c|c|}
\hline Table 1: Pregnancies among patients with FH attending the outpatient lipid clinic in 1992-2015. \\
\hline Pregnant patients (19-45 yrs) & 12 \\
\hline Born children & 18 \\
\hline Pregnancies without treatment & 15 \\
\hline $\begin{array}{c}\text { Pregnancies with unpermitted statin therapy } \\
(20-40 \mathrm{mg} / \text { day) }\end{array}$ & 3 \\
\hline $\begin{array}{c}\text { Genetically proven LDL-R mutations (p.Asp266Glu, } \\
\text { p.Gly952Glu, p.Arg416Trp, FDB-apoB100, and c. 1272. } \\
\text { 1273ins96) }\end{array}$ & 8 \\
\hline History of oral contraceptives & 10 \\
\hline Smokers & 6 \\
\hline Mean value of TC (mmol/l) & 8.2 \\
\hline
\end{tabular}




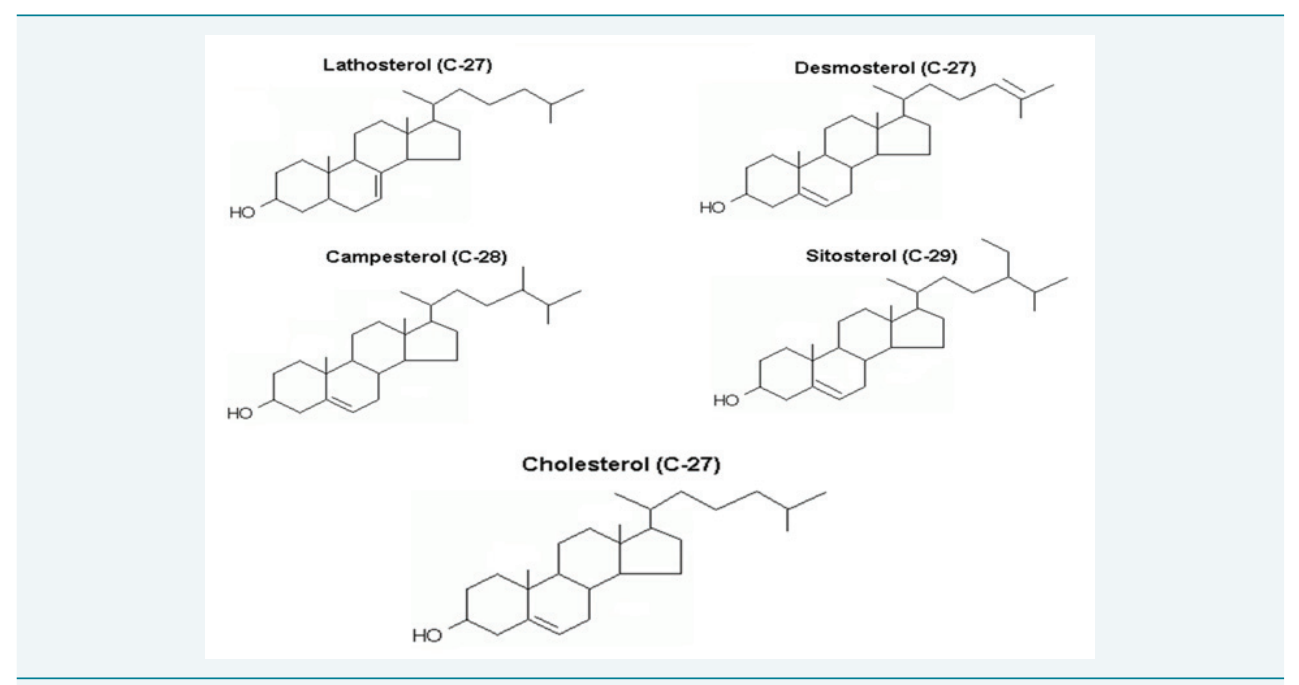

Figure 2: Structures of sterols under discussion: Lat and Des - markers of endogenous synthesis of cholesterol; Cam and Sit - markers of phytosterol absorption in the intestine.

that the main cause of GH lies in the increased endogenous synthesis of cholesterol. The structures of the NCS under discussion here are shown in Figure 2. Last but not least, the idea came to us that measuring the increase of TC between the first trimester and the fifth to sixth month could be highly effective in detecting women with FH in order to lower their dramatically increased CHD risk later in life.

\section{Patients and Methods}

During the certification procedure for the Central Laboratories at the Prague Institute for the Care of Mother and Child conducted by the Czech Accreditation Institute in 2014-2016, 21,000 clinical biochemistry results of healthy pregnant women of different gestational age were being assessed. Among those with $\mathrm{TC}>7 \mathrm{mmol} / \mathrm{l}$ an experimental group of 84 pregnants was randomly chosen for a detailed analysis of their NCS levels. Lathosterol (Lat) and desmosterol (Des) were examined as markers of cholesterol synthesis, whereas sitosterol (Sit) and campesterol (Cam) were used to mark the intestinal absorption of phytosterols.

In the control group of 45 healthy pregnant co-workers in the Na Homolce Hospital, their lipid profile was regularly taken during their pregnancy.

The routine biochemical, hematological and immunological analyses were done using Beckman Coulter and Cobas systems. The vitamins and trace elements were assessed by HPLC and Immulite (DPC); IMT of carotideal arteries by VigmedSound, and LDL-receptor mutations by molecular genetic methods under the international MedPed project to detect FH patients (www.medped.org, [37]).

The NCS levels were established using Gas Chromatography-Mass Spectrometry by a Finnigan Mat 120b with epicholesterol applied as an internal standard (for detailed methodology see Hyánek et al. 2014 [38]).

The statistical assessment was performed using the R software (www.r-project. org). The basic statistical parameters included mean and median values, $95 \%$ confidence intervals, sample size, maximum and minimum values, and the respective standard deviations. The correlation analysis was based on Pearson's product-moment correlation coefficient.

The study has been approved of by the Na Homolce Hospital Ethics Committee. It is part of Project No. NA 7452-3 supported by the Internal Grant Agency of the Czech Ministry of Health (IGA MZ CR). Informed consent for inclusion was obtained from all the participants. 


\section{Results}

Figure 3 documents the development of mean TC values found in the control group of 45 healthy women during their low-risk pregnancy.

Table 2 shows the mean values for the classic lipid fractions in the basic population of 21,000 healthy pregnant women. The mean of the elevated TC levels was $6.8 \mathrm{mmol} / \mathrm{l}$. The record value of $19.6 \mathrm{mmol} / \mathrm{l}$ (!) found in one of the patients and indicative of the homozygote form of $\mathrm{FH}$ was not included in the calculation. The incidence of TC $>7.0 \mathrm{mmol} / \mathrm{l}$ was 1 to 136 (!), and the incidence of TC $>8.0 \mathrm{mmol} / \mathrm{l}$ was 1 to 256 (!) in this population.

Table 3 shows the mean values of standard lipid profile and the NCS within the experimental group of 84 healthy pregnant women with hypercholesterolemia.

Table 4 shows correlations of the classic lipid markers with the NCS under study: a moderate correlation was found of Lat with TC $(r=0.535)$, with LDL-C ( $r=0.364)$, and with non-HDL-C $(r=0.356)$, as well as of Des with TC $(r=0.356)$.

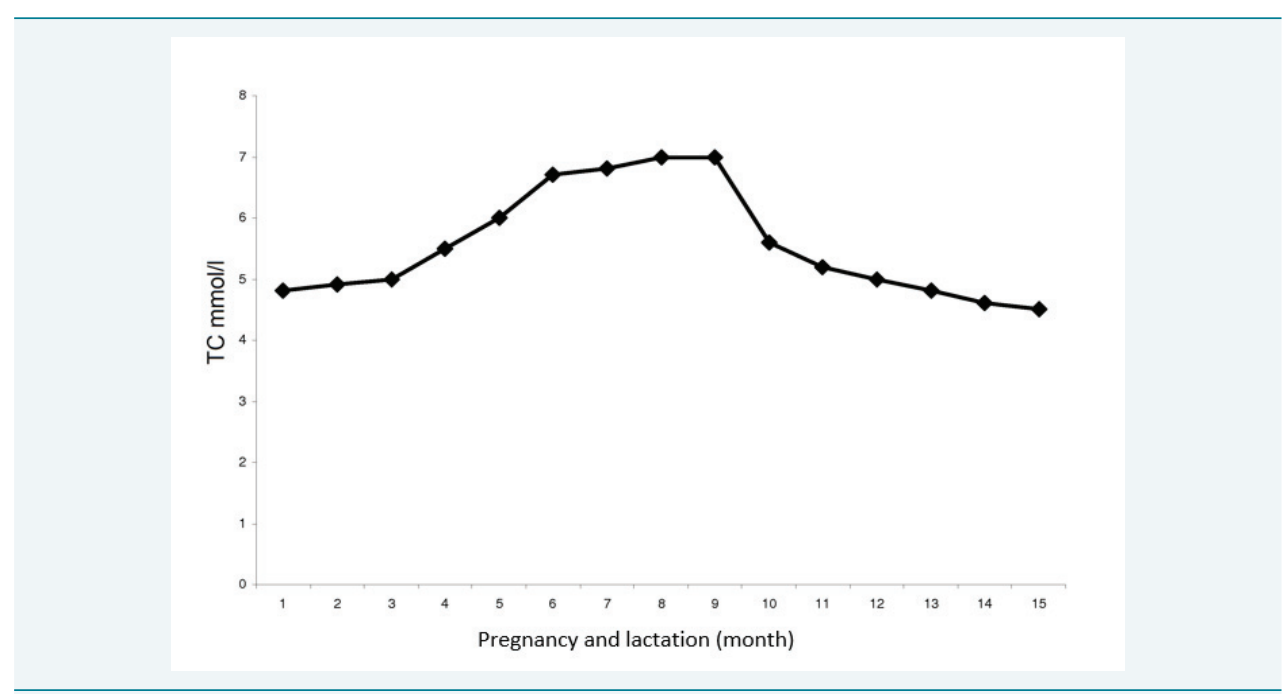

Figure 3: Metabolic changes of total serum cholesterol values during healthy pregnancy and lactation in 45 controls.

Table 2: Mean values of standard lipid serum parameters in the basic population of 21,000 healthy pregnant women (2014-2016).

\begin{tabular}{|c|c|}
\hline & Mean value $(\mathrm{mmol} / \mathrm{l})$ \\
\hline TC & 6.8 \\
\hline LDL-C & 4.6 \\
\hline Non-HDL-C & 4.5 \\
\hline HDL-C & 2.2 \\
\hline TG & 3.9 \\
\hline
\end{tabular}

Table 3: Mean values of standard serum lipid parameters $(\mathrm{mmol} / \mathrm{l})$ and $\mathrm{NCS}(\mu \mathrm{mol} / \mathrm{l})$ in the experimental group of 84 healthy pregnant women with TC $>7.0 \mathrm{mmol} / \mathrm{I}$ (NCS reference values $(\mu \mathrm{mol} / \mathrm{l})$ for healthy non-pregnant women are: Lat 6.4+/-0.7, Des 4.2+/-0.4, Cam 9.7+/-1.0, and Sit 8.7+/-0.8).

\begin{tabular}{|c|c|c|}
\hline & Mean value & Significant deviation \\
\hline TC & 7.2 & 1.2 \\
\hline LDL-C & 4.1 & 1.7 \\
\hline Non-HDL-Cl & 4.5 & 1.3 \\
\hline HDL-C & 1.8 & 0.3 \\
\hline TG & 2.5 & 1.0 \\
\hline Lat & $7.8(p<0.01)$ & 1.7 \\
\hline Des & 4.7 & 0.9 \\
\hline Sit & 9.6 & 3.8 \\
\hline Cam & 9.8 & 2.6 \\
\hline
\end{tabular}


Table 4: Correlation quotients of classical lipid parameters with NCS in the experimental group of 84 hypercholesterolemic pregnant women

\begin{tabular}{|c|c|c|c|c|}
\hline & Lat & Des & Sit & 0.02 \\
\hline TC & 0.53 & 0.35 & 0.26 & 0.02 \\
\hline LDL-C & 0.36 & 0.4 & 0.36 & 0.01 \\
\hline Non-HDL-C & 0.35 & 0.12 & 0.29 & 0.01 \\
\hline TG & 0.02 & 0.01 & 0.02 & 0.01 \\
\hline
\end{tabular}

There was no correlation between the phytosterols and the increased cholesterol synthesis: Sit $(r=0.162)$ a Cam $(r=0.153)$. Neither did we find any compensatory elevation of phytosterols.

Our results prove that the gestational elevation of TC, taking place chiefly in its LDL and non-HDL fractions, is a consequence of the increased endogenous synthesis of cholesterol, as indicated by the Lat and Des elevations. The compensatory decrease in the Sit and Cam levels, which marks lowered absorption of phytosterols, is insignificant. The Lat and TG correlation still remains to be clarified.

Table 5 shows the preliminary results of our active search for gestational FH among the healthy pregnant population in the Prague Institute for the Care of Mother and Child undertaken within the last two years (2017-2018).

As mentioned above, we have found a homozygous FH patient during the research with the record TC level of $19.6 \mathrm{mmol} / \mathrm{l}$. She had preeclampsia and a preterm birth in the $30^{\text {th }}$ gestational week. Unfortunately, she refused the recommended follow-up medical treatment.

Last but not least, below is a case study of one of our 3 heterozygous $\mathrm{FH}$ patients from the Na Homolce Hospital lipid clinic, who took statins (20-40 mg/day) through negligence during the first three months of their asymptomatic pregnancies. They had no pregnancy complications and gave birth to healthy, though preterm and low weight children. The children are now aged from 8 to 12, and their psychomotor development is normal.

\section{Discussion}

In this pilot study into gestational hypercholesterolemia and its causes, we have

(a) proved via the elevated Lat levels that the high TC during pregnancy results from the increased endogenous synthesis of cholesterol;

(b) identified 17 new patients with FH, including 1 with its rare homozygous form; and

(c) discovered a surprisingly high prevalence of elevated TC levels among the healthy pregnant Slavic population.

Unfortunately, our epidemiological findings could not be compared with other European pregnant populations owing to data unavailability.

The current literature on maternal hypercholesterolemia can be roughly divided into three areas of researchers' interest: (a) direct birth outcomes; (b) pathogenic maternal programming; and (c) lipid-lowering therapies during pregnancy.

Apart from the individual and serial case studies reporting on the direct birth outcomes, an association has been repeatedly found on larger cohorts between maternal dyslipidemia and preterm birth [39-42]. A large meta-analysis has discovered a correlation between preeclampsia and maternal hyperlipidemia [22]. Also, impaired physiological decrease in the uteroplacental vascular resistance in pregnant women $\mathrm{FH}$ 


\begin{tabular}{|c|c|}
\hline Detected FH patients & $17(100 \%)$ \\
\hline Uneventful pregnancy & $11(64.7 \%)$ \\
\hline Pregnancy with preeclampsia & $6(35.3 \%)$ \\
\hline Physiological delivery & $6(35.3 \%)$ \\
\hline $\begin{array}{c}\text { Abnormal delivery incl. CS } \\
\text { (cf. } 38.6 \% \text { total hospital CS rate in 2017) }\end{array}$ & $11(64.7 \%)$ \\
\hline Normotrophic fetus & $12(70.5 \%)$ \\
\hline Hypotrophic fetus $(<2500 \mathrm{~g})$ & $5(29.5 \%)$ \\
\hline TC levels (mmol/l) & $10-19.6$ \\
\hline
\end{tabular}

has been reported [43]. According to a very recent study, maternal supraphysiological hypercholesterolemia associates with endothelial dysfunction of the placental microvasculature [44].

Since the 1999 FELIC study [13], numerous trials have shown the adverse effects of maternal hypercholesterolemia during pregnancy on the offspring in both animals and humans [45-51]. Conversely, a recent study did not find and significant differences between biochemistry results of children with maternally inherited FH and paternally inherited FH, concluding that maternal inheritance does not predict cholesterol levels in children with FH, but not excluding the fetal origin of adulthood disease hypothesis at the same time [52].

Traditionally, the dietary and/or medical lowering of high TC levels during pregnancy has been generally considered dangerous and harmful because of the fetal hypotrophies observed in animal experiments and deleterious effects on human first trimester placental explants $[53,54]$. On the other hand, a marked effect of a cholesterol-lowering diet on the reduction of preterm delivery has been observed in low-risk pregnancies $(n=290)$ with no effect on the cord and neonatal lipids [55].

A recent systematic review on the risks of statin use in pregnancy showed no clear relationship of congenital anomalies with statin use in pregnancy, supporting the findings that statins are probably not teratogenic, but concluding at the same time that until more information is available, statins should still be avoided in pregnancy [56].

Botha et al. have recently reported on 25 pregnancies of genetically confirmed homozygous $\mathrm{FH}$ patients exposed to lipid-lowering therapy during gestation, of which 18 were exposed to statin therapy just prior to or during pregnancy. The birth outcomes of statin users were comparable to those untreated [57].

Over the years, many publications finding no significant teratogenic effect from maternal use of statins during pregnancy have called for further research into this kind of therapy, as well as into other lipid-lowering therapies in women with FH during pregnancy [58-62]. We fully subscribe to this idea, bearing in mind how much FH mothers might potentially benefit later in life from the lowered atherogenicity of their pregnancies.

As for statins, our own observation of 3 women with FH who took large doses of statins neglectfully of their pregnancy throughout the first trimester has so far shown preterm delivery/low birth weight and low toxicity of statin treatment. Below is one of these cases reported in a greater detail.

\section{Clinical case report}

Healthy mother, aged 32, laboratory technician, genetically verified heterozygous $\mathrm{FH}, \mathrm{TC}=7.8 \mathrm{mmol} / \mathrm{l}$ on admission with a high risk of cardiovascular event from both sides of the family (SCORE $20 \%$ ), stabilised on TC $=4.8 \mathrm{mmol} / \mathrm{l}$ (40 $\mathrm{mg}$ of simvastatin/ 
day); neurotic personality, poor compliance, IQ 95, BMI 32, history of repeat abortion. The patient had been informed on the potential toxic effects of statins during pregnancy, and she signed a document to interrupt statin treatment before pregnancy. When pregnant, however, she failed to stop the treatment, and did not visit the lipid clinic until urged to do so by friends in the workplace, with whom she talked on her pregnancy. The pregnancy proceeded uneventful until the completed sixth month, when she delivered spontaneously after an exacting hiking trip, giving birth to a female baby, resuscitation not needed, $600 \mathrm{~g}, 32 \mathrm{~cm}$, fed by donor milk, discharged from hospital to a reception centre weighing 2,400 g. At nine years of age, the girl weighed $9 \mathrm{~kg}$, with the head circumference of $45 \mathrm{~cm}$, was somatically well, had psychomotor and mental development scores within the norm for an early preterm infant; started school at 8 years of age; mental development scores at 9, 10 and 11 years of age have been close to upper limit of normal so far; paediatrician and psychologist are satisfied with the previous psychomotor development.

So far, very little has been written on how mothers could benefit in their later life from the diagnosis of FH during pregnancy [23]. We have only found the idea that the changes in LDL patterns during pregnancy might be used in identification of women with atherogenic small and dense LDLs later in life [63]. This area definitely deserves further profound investigation starting with monitoring of GH among other large pregnant populations.

\section{Conclusion}

Our experience gained over the last twenty years of extensive practice and research in the field of hereditary dyslipidemias indicates that FH manifests itself distinctly by highly elevated levels of TC in the fifth to sixth gestational month. By this physiological provocation of augmented cholesterol production, Mother Nature has endowed us with a unique opportunity to screen effectively and efficiently for FH throughout female fertile population. A single more cholesterol measurement within the standard blood test taken towards the end of the second trimester is enough to detect previously unrecognized cases of this still largely underestimated and underdiagnosed disease with further differentiation and treatment possible after delivery and weaning. This, together with more research needed into the possibilities of treatment during pregnancy, opens up enormous potential for cross-specialty cooperation and research of gynecologists/obstetricians and internists/metabologists, where the former will be able to better prevent and properly deal with serious late pregnancy complications, such as hypercholesterolemia-induced late gestosis, and the latter will be able to identify the patients early enough to be able to properly evaluate and deal with their drastically increased cardiovascular risk, including reduction of CHD and prevention of early death. Ultimately, this joint effort will be towards better maternal health as well as health of the offspring in both the short-term and long-term perspective, just in line with Louis Pasteur's words that "chance favours the prepared mind."

\section{Acknowledgement}

Internal Grant Agency of the Czech Ministry of Health (IGA MZ CR) with grant number: NA 7452-3

\section{References}

1. Feingold KR, Wiley T, Moser AH, Lear SR, Wiley MH.De novo cholesterogenesis in pregnancy. J Lab Clin Med. 1983; 101: 256-263. Ref.: http://bit.ly/2KRPVVI

2. Hyánek J. Hypercholesterolemia in pregnancy - pathobiochemical and pathophysiological implication for atherosclerosis and evaluation in metabolic surgery [in Czech with English summary]. Klinická Biochemie a Metabolismus. 2013; 21: 208-214. Ref.: http://bit.ly/2XCE6c4

3. Desoye G, Schweditsch MO, Pfeiffer KP, Zechner R, Kostner GM. Correlation of hormones with lipid and lipoprotein levels during normal pregnancy and postpartum. J Clin Endocrinol Metab. 1987; 64: 704-712. Ref.: http://bit.ly/2KW6BLQ 
4. Amundsen AL, Khoury J, Iversen PO, Bergei C, Ose L, et al. Marked changes in plasma lipids and lipoproteins during pregnancy in women with familial hypercholesterolemia. Atherosclerosis. 2016; 189: 451-457. Ref.: http://bit.ly/2YrwSVx

5. Herrera E, Amusquivar E, López-Soldado I, Ortega H. Maternal lipid metabolism and placental lipid transfer. Horm Res. 2006; 65(supp 3): 59-64. Ref.: http://bit.ly/2xrmAbT

6. Woollett LA. Maternal cholesterol in fetal development: transport of cholesterol from the maternal to the fetal circulation 1-5. The Am J Clin Nutr. 2006; 82: 1155-1161. Ref.: http://bit.ly/2FMiolt

7. Chiang $\mathrm{C}$, Litingtung $\mathrm{Y}$, Lee $\mathrm{E}$, Young KE, Corden JL, et al. Cyclopia and defective axial patterning in mice lacking Sonic hedgehog gene function. Nature. 1996; 383: 407-413. Ref.: http://bit.ly/2NsMsiH

8. Bertrand N, Dahmane N. Sonic hedgehog signalizing in forebrain development and its interactions with pathways that modify its effects. Trends Cell Biol. 2006; 16: 597-605. Ref.: http://bit.ly/31Xi1 Ei

9. Herman GE. Disorders of cholesterol biosynthesis: prototypic metabolic malformations syndromes. Hum Mol Genet. 2003; 12(sup 1, 2): R75-R88. Ref.: http://bit.ly/2XHK8bg

10. Hoffmann GF, Nyhan WL, Zschocke J, Kahler SG, Mayatepek E. Inherited metabolic diseases. Philadelphia: Lippincott Williams \& Wilkins. 2002. Ref.: http://bit.ly/3240gDt

11. Porter FD, Herman GE. Malformation syndromes caused by disorders of cholesterol synthesis. J Lipid Res. 2010; 52: 6-34. Ref.: http://bit.ly/3210SrC

12. Palinski W. Maternal-fetal cholesterol transport in the placenta: Good, bad, and target for modulation. Circ Res. 2009; 104: 569-571. Ref.: http://bit.ly/2KScvxp

13. Napoli C, Glass CK, Witztum JL, Deutsch R, D'Armiento FP, et al. Influence of maternal hypercholesterolaemia during pregnancy on progression of early atherosclerotic lesions in childhood: Fate of Early Lesions in Children (FELIC) study. Lancet. 1999; 354: 1234-41. Ref.: http://bit.ly/2xrJtw1

14. Bartels $\mathrm{A}, O^{\prime}$ Donoghue K. Cholesterol in pregnancy: A Review of knowns and unknowns. Obstet Med. 2011; 4: 147-151. Ref.: http://bit.ly/323sL45

15. Martin U, Davies C, Hayavi S, Hartland A, Dunne F. Is normal pregnancy atherogenic? Clin Sci (Lond). 1999; 96: 421-425. Ref.: http://bit.ly/2KSiYbA

16. Vogt A. The genetics of familial hypercholesterolemia and emerging therapies. Appl Clin Genet. 2015; 8: 27-36. Ref.: http://bit.ly/2RM6qn1

17. WiegmanA,GiddingSS2, WattsGF3,ChapmanMJ4,GinsbergHN, etal.Familialhypercholesterolaemia in children and adolescents: Gaining decades of life by optimizing detection and treatment. Eur Heart J. 2015; 36: 2425-2437. Ref.: http://bit.ly/32131VX

18. Nordestgaard BG, Chapman MJ, Humphries SE, Ginsberg HN, Masana L, et al. Familial hypercholesterolaemia is underdiagnosed and undertreated in the general population: guidance for clinicians to prevent coronary heart disease: Consensus statement of the European Atherosclerosis Society. Eur Heart J. 2013; 34: 3478-3490. Ref.: http://bit.ly/2Nqvlhm

19. Glueck CJ, Christopher C, Tsang RC, Mellies MJ. Cholesterol-free diet and the physiologic hyperlipidemia of pregnancy in familial hypercholesterolemia. Metabolism. 1980; 29: 949-955. Ref.: http://bit.ly/2KVwTxB

20. Salameh WA, Mastrogiannis DS. Maternal hyperlipidemia in pregnancy. Clinical obstetrics and gynecology. 1994; 37: 66-77. Ref.: http://bit.ly/2XqUxsQ

21. Toleikyte I, RetterstøI K, Leren TP, Iversen PO. Pregnancy outcomes in familial hypercholesterolemia: A register-based study. Circulation. 2011; 124: 1606-1614. Ref.: http://bit.ly/2ZYIK1A

22. Spracklen CN, Smith CJ, Saftlas AF, Robinson JG, Ryckman KK. Maternal hyperlipidemia and the risk of preeclampsia: A Meta-analysis. Am J Epidemiol. 2014; 180: 346-358. Ref.: http://bit.ly/2KS7tkF

23. Hyánek J, Pehal F, Dubská L, Míková B, Gombíková L, et al. Hypercholesterolemia during pregnancy is caused by increased endogenous cholesterol synthesis. Let's use it for screening of familial hypercholesteroemias too! Journal of Nutritional Therapeutics. 2018;6:79-83. Ref.: http://bit.ly/2LD1 JKW

24. Wadsack C, Hammer A, Levak-Frank S, Desoye G, Kozarsky KF, et al. Selection cholesterol ester uptake from high density lipoprotein by human first trimester and villous trophoblast cells. Placenta. 2003; 24: 131-143. Ref.: http://bit.ly/305EOvS

25. Bhattacharjee J, letta F, Giacomello E, Bechi N, Romagnoli R, et al. Expression and localisation of ATP binding cassette transport $\mathrm{A} 1$ ( $\mathrm{ABCAl}$ ) in the first trimester and term human placenta. Placenta. 2010; 31: 423-430. Ref.: http://bit.ly/2XjLBFy 
26. Stefulj J, Panzenboeck U, Becker T, Hirschmugl B, Schweinzer C, et al. Human endothelial cells of the placental barrier efficiently deliver cholesterol to the foetal circulation via ABCA1 a ABCG-1. Circ Res. 2009 104: 600-608. Ref.: http://bit.ly/2NrMqYo

27. Beigel Y, Bar J, Cohen M, Hod M. Pregnancy outcome in familial homozygous hypercholesterolemic females treated with long-term plasma exchange. Acta obstetricia et gynecologica scandinavica. 1998; 77: 603-608. Ref.: http://bit.ly/2J3R4Hw

28. Anedda S, Mura S, Marcello C, Pintus P. HELP LDL-apheresis in two cases of familial hypercholesterolemic pregnant women. Transfus Apher Sci. 2011; 44: 21-24. Ref.: https://tinyurl. com/y43adqp8

29. Bláha M, Lánská M, Bláha V, Boudyš L, Žák, P. Pregnancy in homozygous familial hypercholesterolemia: Importance of LDL-apheresis. Atheroscler Suppl. 2015; 18: 134-139. Ref.: https://tinyurl.com/ yysgfv5p

30. Eapen DJ, Valiani K, Reddy S, Sperling L. Management of familial hypercholesterolemia during pregnancy: case series and discussion. J Clin Lipidol. 2012; 6: 88-91. Ref.: https://tinyurl.com/ y6z9srmb

31. Kusters DM, Homsma SJM, Hutten BA, Twickler M, Avis HJ, et al. Dilemmas in treatment of women with familial hypercholesterolaemia during pregnancy. Neth J Med. 2010; 68: 299-303. Ref.: https://tinyurl.com/yykheef8

32. Kempten HJM, Glatz JFC, Gevers Leuven JA, van der Voort HA, Katan MB. Serum lathosterol concentration is an indicator for whole-body cholesterol synthesis in humans. J Lipid Res. 1988; 29: 1149-1155. Ref.: https://tinyurl.com/y4r8egpr

33. Teunissen $\mathrm{CE}$, de Vente J, von Bergman K, Bosma H, van Boxtel MPJ, et al. Serum cholesterol precursors and metabolites and cognitive performance in an aging population. Neurobiol Aging. 2003; 24: 147-155. Ref.: https://tinyurl.com/y5kbqh55

34. Miettinen TA, Gylling H. Effect of statins on noncholesterol levels: Implication for use of plant stanols and sterols. Am J Cardiol. 2005; 96: 40D-46D. Ref.: https://tinyurl.com/y435nqfd

35. Hyánek J, Pehal F, Dubská L, Dvořáková J, Mat'oška V, et al. Noncholesterol sterols in healthy children and during the dietary treatment of hypercholesterolemias. [in Czech with English summary]. Česko-slovenská pediatrie. 2006; 61: 493-501.

36. Lupatelli G, Pirro M, Siepi D, Mannarino MR, Roscini AR, et al. Non-cholesterol sterols in different forms of primary hyperlipidemias. Nutr Metab Cardiovasc Dis. 2012; 22: 231-236. Ref.: https://tinyurl.com/y2nhgpt9

37. Vrablík M, Vaclová M, Tichý L, Soska V, Bláha V, et al. Familial hypercholesterolemia in the Czech Republic: More than 17 years of systematic screening within the MedPed Project. Physiol Res. 2017; 66: S1-S9. Ref.: https://tinyurl.com/yxrvlbal

38. Hyánek J, Pehal F, Dubská L, Martiníková V, Privarová J, et al. Lathosterol and noncholesterol sterols in routine use for the differentiation and monitoring of dietary and drug induced treatment of hypercholesterolemias in children and adolescents. Journal of nutritional therapeutics. 2014; 3 : 1-12.

39. Mudd LM, Holzman CB, Catov JM, Senagore P, Evans R. Maternal lipids at mid-pregnancy and the risk of preterm delivery. Acta Obstet Gynecol Scand. 2012; 91: 726-735. Ref.: https://tinyurl.com/ y2st443j

40. Catov JM, Bodnar LM, Kevin E. Early pregnancy lipid concentrations and spontaneous preterm birth. Am J Obstet Gynecol. 2007; 197: 610-617. Ref.: https://tinyurl.com/y4n92nvt

41. Edison RJ, Berg K, Remaley A, Kelley RI, Rotimi C. Adverse birth outcome among mothers with low serum cholesterol. Pediatrics. 2007; 120: 723-733. Ref.: https://tinyurl.com/y2t69m7e

42. Smith CJ, Baer RJ, Oltman SP, Breheny PJ, Bao W, et al. Maternal dyslipidemia and risk for preterm birth. PLOS One. 2018; 13: e0209579. Ref.: https://tinyurl.com/yykvhfbq

43. Khoury J, Amundsen AL, Tonstad S, Henriksen T, Ose L. Evidence for impaired physiological decrease in the uteroplacental vascular resistance in pregnant women with familial hypercholesterolemia. Acta Obstet Gynecol Scand. 2009; 88: 222-226. Ref.: https://tinyurl.com/yxfszygb

44. Fuenzalida B, Sobrevia B, Cantin C, Carvajal LP, Salsoso R, et al. Maternal supraphysiological hypercholesterolemia associates with endothelial dysfunction of the placental microvasculature. Sci Rep. 2018; 8: 7690. Ref.: https://tinyurl.com/yxewc5fb

45. Palinski W, Napoli C. Pathophysiolocial events during pregnancy influence development of atherosclerosis in humans. Trends Cardiovasc Med. 1999; 9: 205-214. Ref.: https://tinyurl.com/ yyfhihjy 
46. Palinski W, Dármiento FP, Vitzum JL, de Nigris FM, Casanada F, et al. Maternal hypercholesterolemia and treatment during pregnancy influence the long-term progression of atherosclerosis in offspring of rabbits. Circ Res. 2001; 89: 991-996. Ref.: https://tinyurl.com/yxdeonjs

47. Palinski W, Napoli C. The fetal origins of atherosclerosis: maternal hypercholesterolemia, and cholesterollowering or antioxidant treatment during pregnancy influence in utero programming and postnatal susceptibility to atherogenesis. FASEB J. 2002; 16: 1348-1360. Ref.: https://tinyurl.com/yxqbv966

48. deAssis SM, Seguro AC, Helou CMB. Effects of maternal hypercholesterolemia on pregnancy and development of offsprings. Pediatric Nephrology. 2003; 18: 328-334.

49. Goharkhay N, Tamayo E, Yin H, Hankins GD, Saade GR, et al. Maternal hypercholesterolemia leads to activation of endogenous cholesterol synthesis in the offspring. Am J Obstet Gynecol. 199: 273. e1-273.e6. Ref.: https://tinyurl.com/y6eu3a4m

50. van den Graaf A, Vissers MN, Gaudet D, Brisson D, Sivapalaratnam S. Dyslipidemia of mothers with familial hypercholesterolemia deteriorates lipids in adult offspring. Arterioscler Thromb Vasc Biol. 2010; 30: 2673-2677. Ref.: https://tinyurl.com/y2nuf6zr

51. Dumolt JH, Radhakrishnan SK, Moghadasian MH, Le K, Patel MS, et al. Maternal hypercholesterolemia enhances oxysterol concentration in mothers and newly weaned offspring but is attenuated by maternal phytosterol supplementation. J Nutr Biochem. 2018; 52: 10-17. Ref.: https://tinyurl.com/y6eaztyb

52. Narverud I, van Lennep JR, Christensen JJ, Versmissen J, Gran JM, et al. Maternal inheritance does not predict cholesterol levels in children with familial hypercholesterolemia. Atherosclerosis. 2015 243: 155-160. Ref.: https://tinyurl.com/y3gd84dw

53. Kenis I, Tartakover-Matalon S, Cherepnin N, Drucker L, Fishman A, et al. Simvastatin has deleterious effects on human first trimester placental explants. Hum Reprod. 2005; 20: 2866-2872. Ref.: https://tinyurl.com/y4sxdq4e

54. Forbes K, ShahVK, Siddals K, Gibson M, Aplin JD, et al. Statins inhibit insulin-like growth factor action in first trimester placenta by altering insulin-like growth factor 1 receptor glycosylation. Mol Hum Reprod. 2015; 21: 105-114. Ref.: https://tinyurl.com/y4x9rkef

55. Khoury J, Henriksen T, Christophersen B, Tonstad, S. Effect of a cholesterol-lowering diet on maternal cord, and neonatal lipids, and pregnancy outcome: A randomized clinical trial. Am J Obstet Gynecol. 2005; 193: 1292-1301. Ref.: https://tinyurl.com/y4tc5uub

56. Karalis DG, Hill AN, Clifton S, Wild RA. The risks of statin use in pregnancy: A systematic review. J Clin Lipidol. 2016; 10: 1081-1090. Ref.: https://tinyurl.com/yybgbol5

57. Botha TC, Pilcher GJ, Wolmarans K, Blom DJ, Raalb FJ. Statins and other lipid-lowering therapy and pregnancy outcomes in homozygous familial hypercholesterolaemia: A retrospective review of 39 pregnancies. Atherosclerosis. 2018; 277: 502-507. Ref.: https://tinyurl.com/y6htv3zh

58. Ofori B, Rey E, Bérard S. Risk of congenital anomalies in pregnant users of NSAIDs. British journal of clinical pharmacology. 2007; 64: 496-509.

59. Avis HJ, Hutten BA, Twickler MT, Kastelein JJP, van der Post J, et al. Pregnancy in women suffering from familial hypercholesterolemia: A harmful period for both mother and newborn? Curr Opin Lipidol. 2009; 20: 484-490. Ref.: https://tinyurl.com/y6rcv5w8

60. Godfrey LM, Erramouspe J, Cleveland K. Teratogenic risk of statins in pregnancy. Ann Pharmacother. 2012; 46: 1419-1424. Ref.: https://tinyurl.com/y38az8rf

61. Bateman BT, Hernandez-Diaz S, Fischer MA, Seely EW, Ecker JL, et al. Statins and congenital malformations: Cohort study. BMJ. 2015; 350: h1035. Ref.: https://tinyurl.com/y4dumxg4

62. Nasioudis D, Doulaveris G, Kanninen TT. Dyslipidemia in pregnancy and maternal-fetal outcome. Minerva Ginecol. 2019; 71: 155-162. Ref.: https://tinyurl.com/y6zf9zad

63. Brizzi P. Tonolo G, Esposito F, Puddu L, Dessole S, et al. Lipoprotein metabolism during normal pregnancy. American journal of obstetrics and gynecology. 1999; 181: 430-434. 